ISSN: 0514-7336

DOI: http://dx.doi.org/10.14201/zephyrus201473197216

\title{
UN THORACATUS IMPERIAL EN LOS BAÑALES (UNCASTILLO, ZARAGOZA)
}

\section{An imperial thoracatus from Los Bañales (Uncastillo, Zaragoza)}

\author{
Luis Romero Novella*, Javier Andreu Pintado* y María del Mar Gabaldón Martínez** \\ * Dpto. Historia Antigua. UNED. C/ Senda del Rey, 9. 28040 Madrid. Correo-e: jandreu@geo.uned.es. \\ **Universidad CEU San Pablo. C/ Julián Romea, 18. 28003 Madrid. Correo-e: mgab.ihum@ceu.es
}

Recepción: 21/11/2014; Revisión: 6/02/2014; Aceptación: 12/04/2014

BIBLID [0514-7336 (2014) LXXIII, enero-junio; 197-216]

RESUMEN: El presente trabajo informa sobre el hallazgo de un conjunto de fragmentos escultóricos recuperados en contexto de amortización secundario en el foro de la ciudad romana de Los Bañales (Uncastillo, Zaragoza) durante el verano de 2013. Este conjunto de piezas realizadas en mármol de Carrara incluye la parte inferior y central de una coraza profusamente decorada con escenas de spolia hostium, así como las piernas y zona de la cintura de una estatua junto a otros elementos pertenecientes a la misma -hombro, mano y fragmentos de las pterykes y del paludamentum-. Se plantea la probable adscripción de los fragmentos presentados a una única thoracata imperial probablemente -a juzgar por diversos detalles iconográficos de la coraza y formales del resto de la pieza- de fecha domicianea. Además se pone a la thoracata en relación con lo que sabemos de este singular municipio flavio del convento Cesaraugustano planteando, incluso, una hipótesis sobre la ubicación primaria del monumento en una de las scholae del pórtico occidental del foro de Los Bañales.

Palabras clave: Escultura romana. Iconografía imperial. Spolia hostium. Domiciano. Forum. Mármol de Carrara.

ABSTRACT: The following paper presents a serie of pieces of Roman sculpture in white marble from Carrara attested during summer of 2013 in reused and amortization context right in the forum of the Roman town of Los Bañales (Uncastillo, Zaragoza). Between the pieces presented here particular attention is paid to the central part of a great quality decorated breastplate with images of spolia hostium and to the legs and feet of the sculpture including also other small parts -shoulder, hand and pieces of the pterykes and of the paludamentum - of that one, here considered as part of an unique imperial thoracatus probably from Domitian times according to some parallels and some formal details of the statue itself. That sculpture is here linked with the history of this very singular Flavian municipality of the Caesaraugustan conventus presenting, also, a hypothesis about the primary position of the monument, in one of the scholae of the occidental porticus in the forum of Los Bañales.

Key words: Roman sculpture. Roman iconography. Spolia hostium. Domitian. Forum. Carrara marble. 


\section{Introducción: el hallazgo y su contexto ${ }^{1}$}

Al N del antiguo conuentus Caesaraugustanus, en la actual comarca aragonesa de las Cinco Villas, al s del término municipal de Uncastillo (Zaragoza), se vienen excavando desde hace seis años los restos de una monumental ciudad romana -en boga entre Augusto y los Flavios (Andreu,

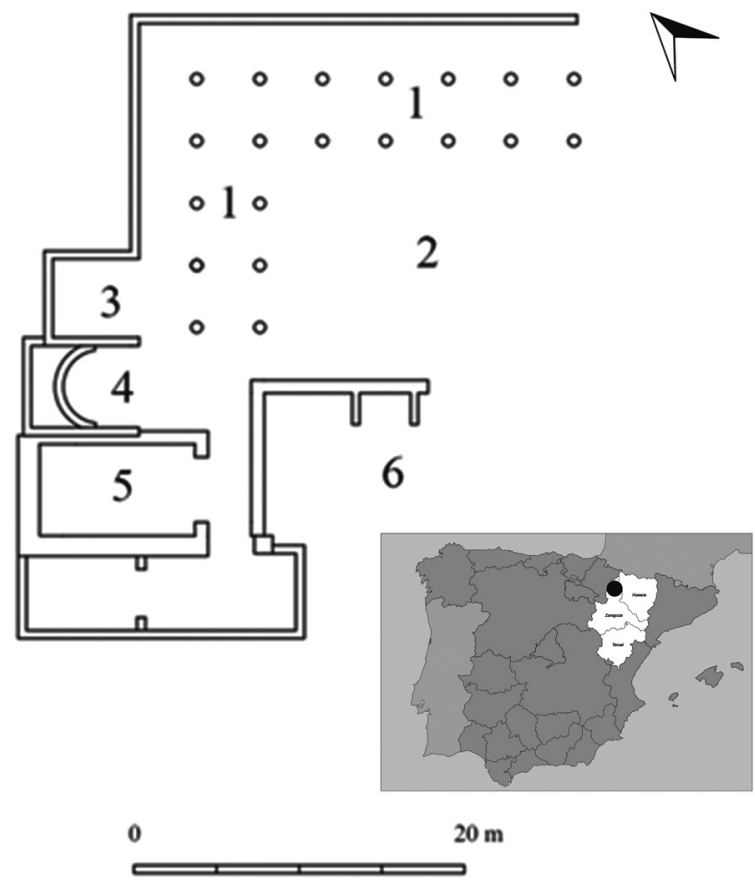

FIG. 1. Localización del yacimiento y planta del foro de Los Bañales con indicación del lugar de aparición del depósito de estatuaria: 1) porticus duplex, septentrional y occidental; 2) ambulacrum central; 3) recinto de representación de Victoria Aug(usti); 4) recinto votivo promovido por Pomp(eia) Paulla; 5) espacio de representación indeterminado; 6) substrucción meridional, lugar del hallazgo (J. J. Bienes, J. Andreu y L. Romero).

${ }^{1}$ El presente trabajo se integra en las actividades del Plan de Investigación que - por encargo y financiación del Dpto. de Educación y Cultura del Gobierno de Aragón y la dirección de la Fundación Uncastillo- se viene llevando a cabo en el yacimiento de Los Bañales (Uncastillo, Zaragoza) (http://www.losbanales.es). Su contenido se ha visto notablemente enriquecido por las aportaciones de los informantes anónimos para los que se quiere dejar aquí constancia pública de gratitud.
2011: 29-45) - conocida de antiguo y dotada de un singular foro aún en proceso de excavación ${ }^{2}$. Este, seguramente edificado en época de Augusto $-o$ incluso algo antes- sobre estructuras republicanas, debió comenzar su proceso de amortización a partir de época antonina. En una de las substrucciones de cimentación de la parte meridional de la plaza (Fig. 1), en julio de 2013, se produjo el hallazgo de cerca de 40 fragmentos escultóricos -la mayoría de ellos en mármol blanco (Fig. 2) que, necesariamente, se relacionan con otros localizados próximos y en equivalencia estratigráfica en anteriores campañas ${ }^{3}$. A priori el conjunto parece corresponder a un depósito de amortización de estatuaria relacionado con algún horno de cal todavía sin localizar, pero para el que no faltan indicios razonables, como la constatación de evidencias de quemado en algunos de los fragmentos marmóreos hallados ${ }^{4}$. En dicho corpus de materiales -fundamentalmente constituido por fragmentos con restos de pliegues de vestimenta y con zonas de anatomía humana desnuda- se individualiza una serie de fragmentos, posiblemente pertenecientes a una única estatua que, por ahora, sería la única evocación imperial conocida en la ciudad romana de Los Bañales.

Lo inusual del hallazgo en el contexto del Valle del Ebro -tan parco en estatuaria romana (cf. propuesta de inventario en Andreu, 20042005: 272-273, n. 116)-y el hecho de que, en el conjunto de los referidos fragmentos, destaquen los que apuntan al carácter imperial de la estatua de la que -muy probablemente- formaban parte originaria nos ha parecido razón suficiente para compartir con la comunidad

\footnotetext{
${ }^{2}$ Andreu, J.; Bienes, J. J. y Jordán, Á. A.: "Monumentalización y regresión urbanas en un municipio del norte del convento jurídico Cesaraugustano: Los Bañales de Uncastillo". En ¿Crisis de las ciudades al final del Alto Imperio? Murcia, en prensa.

${ }^{3}$ Jordán, Á. A. y Andreu, J.: "Un nuevo conjunto epigráfico en el foro de Los Bañales (Uncastillo, Zaragoza)", Archivo Español de Arqueología, 87, en prensa.

${ }^{4}$ Para el contexto $c f$. Andreu, J.; Bienes, J. J.; Lasaosa, E. y Romero, L.: "El foro de la ciudad romana de Los Bañales (Uncastillo, Zaragoza): aspectos estructurales y cronológicos preliminares". En Actas XVIII Congreso Internacional de Arqueología Clásica (Mérida, 2013). Mérida, en prensa.
} 
científica una valoración tipológica y preliminar del hallazgo; somos conscientes, sin embargo, de que esta tendrá necesariamente un carácter provisional y merecerá un estudio -con todo el corpus de fragmentos- futuro cuando se contextualice toda la documentación estatuaria del foro. Sí queremos dejar constancia de que la variedad del material localizado -como antes se anotó de modo sucinto- encaja perfectamente con el tipo de representaciones escultóricas que están ofreciendo los foros hispanos -por ejemplo, $c f$. Moreno, 2007- y con el carácter de espacios de representación que los intercolumnios de las porticus duplices y las scholae del foro de Los Bañales debieron tener ${ }^{5}$.

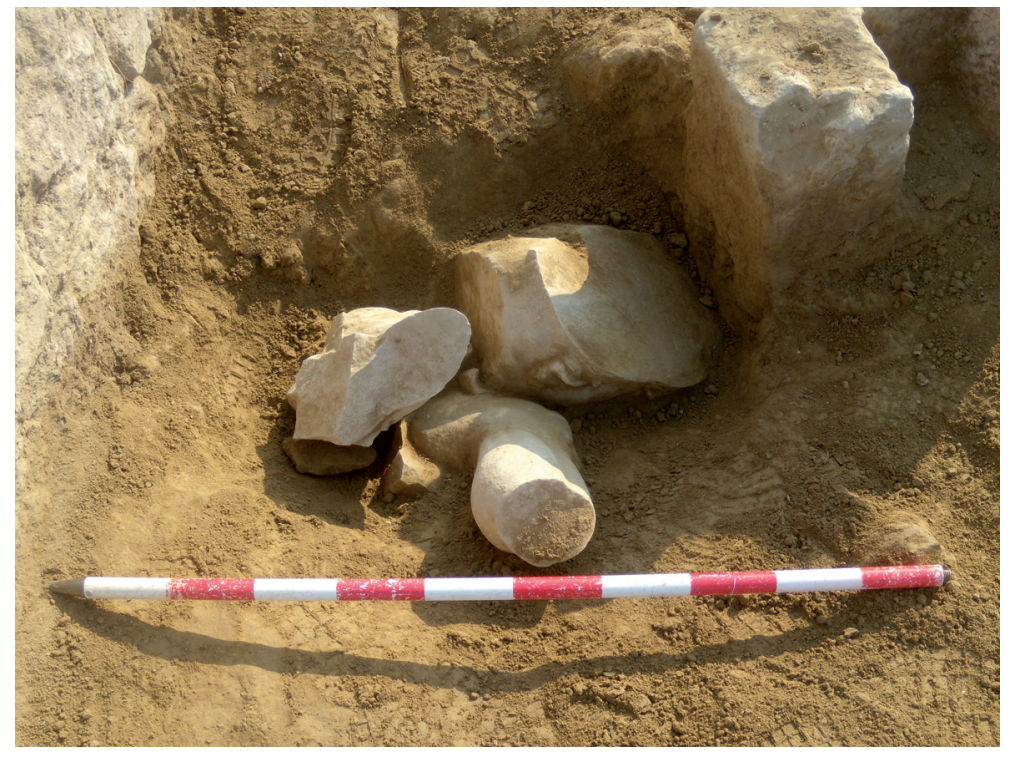

FIG. 2. Momento del hallazgo de las piernas y la coraza del thoracatus (I. Barragán).

\section{Los fragmentos escultóricos: inventario y estudio}

\subsection{Fragmento de coraza (Fig. 3)}

a) Ficha técnica

Material: Mármol blanco de Carrara, Italia (cf. Anexo).

Dimensiones: alt. máx.: $44 \mathrm{~cm}$; anch. máx: $34,50 \mathrm{~cm}$, y gr. máx.: $33 \mathrm{~cm}$.

Conservación: buena, aunque se trata de un fragmento cortado ya en la antigüedad, tal vez en relación al proceso de amortización que afectó a la estatua. Presenta una fractura oblicua en su parte superior y transversal en la inferior, que ha causado desperfectos en las dos figuras centrales, en la zona de contacto con la fractura oblicua. En la figura de la izquierda se aprecian también desperfectos en cabeza y brazo izquierdo conservándose, sin embargo, la imagen gemela de la derecha de modo casi completo. Como el resto de fragmentos, está pendiente de inventario en relación a la continuidad de los trabajos arqueológicos en la unidad de que aquellos proceden,

\footnotetext{
${ }^{5}$ Andreu, Bienes, Lasaosa y Romero: op. cit. n. 3.
}

custodiándose por parte de la Fundación Uncastillo, responsable del proyecto de investigación en Los Bañales.

b) Descripción y análisis iconográfico: la pieza es parte del torso del thoracatus (Plin. HN. 34, 10, 18-19; 35, 36, 69 y 37, 37, 118; cf. además Ojeda, 2011: 137) que está modelado de forma detallada y pulcra. Se aprecian dos valvas unidas con bisagras laterales. En la parte conservada figura una decoración con escenas de spolia hostium. Hay un motivo central principal y dos secundarios laterales. El central parece ofrecer un tropaion, del que se conserva sólo el pie (Fig. 4). A este, en su parte derecha, se encuentra atado un robusto cautivo, desnudo y sentado sobre tres escudos de diversa tipología; a la izquierda hay otro prisionero del que sólo se conservan las piernas entrecruzadas, sin que se aprecie si se encontraba también atado al trofeo. Como el anterior, está sentado también sobre tres escudos. Destacan en ambos conjuntos tres escudos con barra de refuerzo central alargada presente en las armas de tradición celta (Rapin, 1999: 46-47; Lejars, 2011: 135-136). En el lado derecho de la coraza se representa a otro prisionero desnudo y también bastante robusto sobre otros tres escudos. Su pierna izquierda está flexionada y 


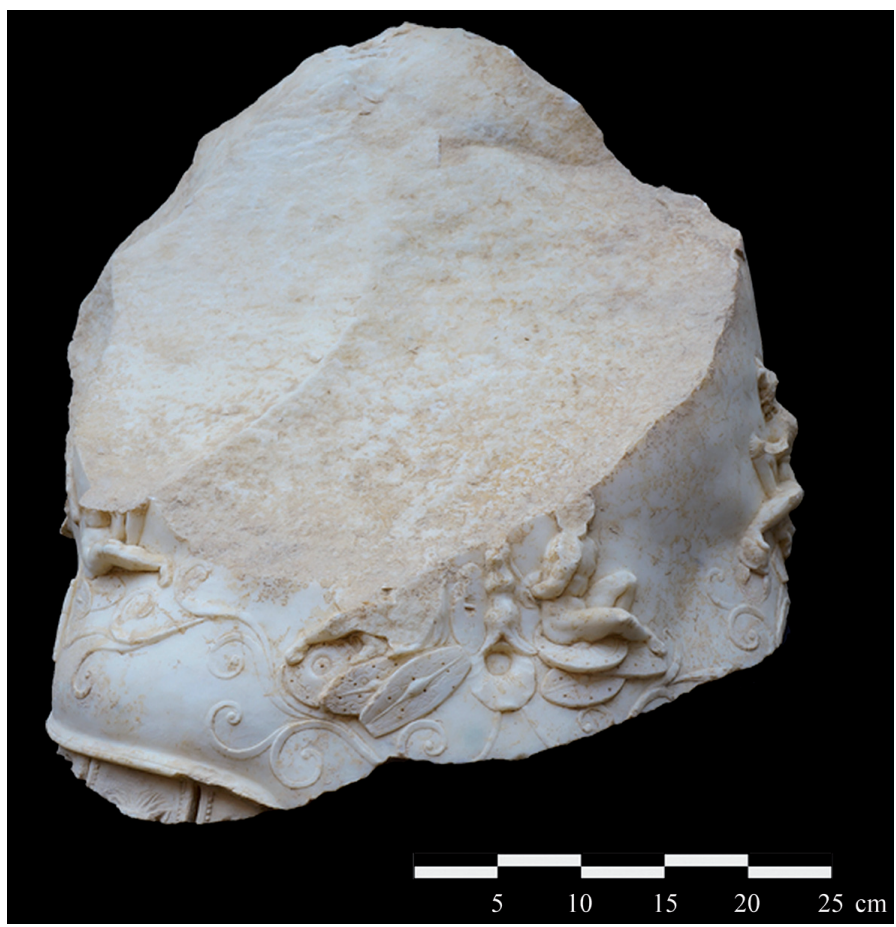

FIG. 3. Fragmento de la coraza del thoracatus de Los Bañales (fotog. Paleorama).

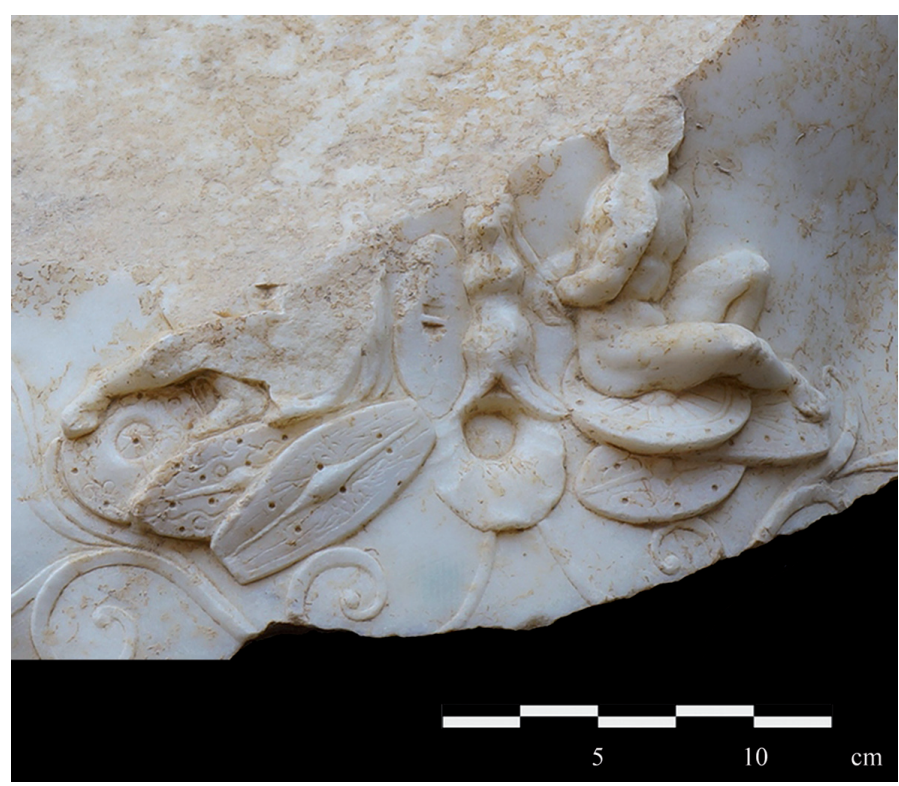

FIG. 4. Detalle del motivo central de la coraza del thoracatus de Los Bañales (fotog. Paleorama). la derecha sin flexionar, sobre los escudos. El lado izquierdo de la coraza lo ocupa una figura femenina (Fig. 5) menos robusta que los prisioneros anteriores. Está sentada sobre un único escudo y apoya el pie izquierdo sobre un casco. No se encuentra atada y se dispone en una actitud reposada. No está desnuda sino que parece vestir las braccae típicas de los pueblos germanos de las que contamos con numerosos ejemplos en los relieves de la columna de Marco Aurelio (Caprino et al., 1955: 88-89, lám. XVI, 90-91, lám. XX y 102-103, lám. LXI, entre otros), en el sarcófago de Portonaccio (Pardyová, 2004: 62-64; España, 2011: 99) o en los sarcófagos grande y pequeño de Ludovisi (De Angelis, 2002: 218-221, 234235). Su torso recuerda a la descripción que Tácito hace de las mujeres germanas (Tac. Germ. 17). La parte inferior y lateral está decorada con sencillos racimos de hojas de acanto. En la parte inferior derecha se conserva el arranque de varios pteryges. En uno de ellos se conserva la oreja izquierda y la melena de un posible felino, tal vez un lince o un león con melena corta (Stemmer, 1978: 163 J y L).

c) Historia del motivo, paralelos e identificación: el motivo central de la coraza de la thoracata de Los Bañales es sin duda uno de los más emblemáticos dentro del repertorio de la iconografía de la victoria. La imagen del tropaion con cautivos a sus pies, originaria del mundo helenístico, fue heredada por Roma para convertirse, desde el final de la República y a lo largo de todo el Imperio, en uno de los motivos más frecuentes del arte triunfal; aparece en arcos de triunfo y en estatuas imperiales, pero también en los reversos monetales, en piedras preciosas y en sarcófagos militares, en los que a partir del s. II d. C. aparecen escenas de cautivos atados al trofeo, a veces sobre los spolia, como forma de glorificar la virtus del soldado, emanación de la virtud personal del emperador, la virtus Augusti (Castellví, 2003: 460). Y es que, como ya señaló Picard, el trofeo se convirtió en una especie 
de imagen personal del vencedor, simbolizando su poder y la supremacía de Roma tanto en tiempos de César (Picard, 1957: 225) como, especialmente, a partir de Augusto (Picard, 1957: 231).

Con todo, el significado primigenio del tropaion, de origen griego, era señalar la victoria en el propio campo de batalla, a través de las armas capturadas al enemigo, que se colgaban en un tronco de árbol, dándole una apariencia humana y dedicándose a los dioses, en especial a Zeus Tropaios (Betalli, 2009; Gabaldón, 2005; Rabe, 2008). Desde el punto de vista jurídico, el tropaion era el límite, tanto simbólico como geográfico, que los vencedores imponían a los vencidos; dado su carácter sacro era inviolable. Asimismo, no podía haber victoria sin trofeo ni trofeo sin victoria. En ocasiones, cuando el hecho de la victoria no estaba claro o ambos contendientes la

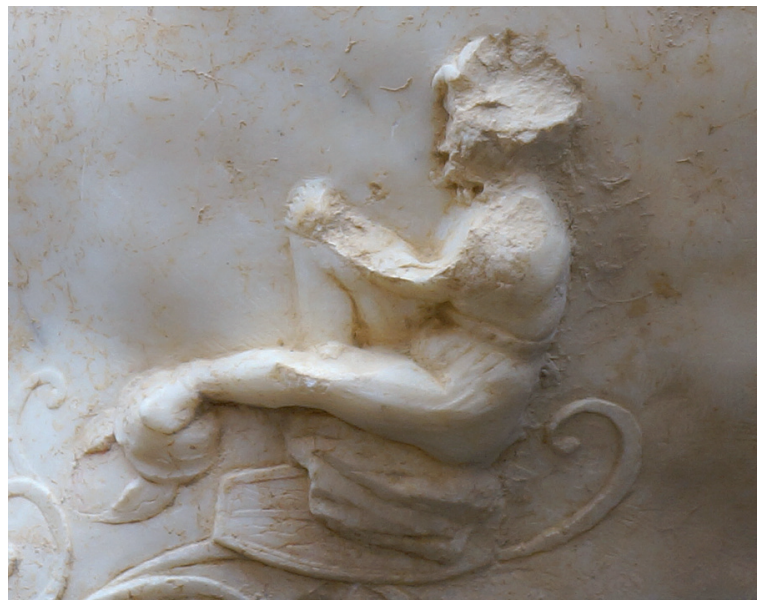

FIG. 5. Detalle de la posible representación de Germania en el lateral de la coraza de Los Bañales (fotog. Paleorama).

\begin{tabular}{|c|c|c|c|}
\hline & Procedencia & LOCALIZACIÓN & BIBLIOGRAFÍA \\
\hline 1 & $\begin{array}{l}\text { Amastris } \\
\text { (Amasra, Turquía) }\end{array}$ & Museo Arqueológico de Estambul (Turquía) & $\begin{array}{l}\text { Vermeule, 1959: 50, n. }{ }^{\circ} 140 \\
\text { Stemmer, 1978: III, } 12\end{array}$ \\
\hline 2 & \begin{tabular}{|l} 
Castrum Nouum \\
(Giulianova, Italia)
\end{tabular} & Museos Vaticanos (Ciudad del Vaticano) & $\begin{array}{l}\text { Gergel, 2001: 202-203; } \\
\text { Cadario, 2004: 341-347 }\end{array}$ \\
\hline 3 & $\begin{array}{l}\text { Gabii } \\
\text { (Roma, Italia) }\end{array}$ & Museo del Louvre de París (Francia) & $\begin{array}{l}\text { Kersauson, 1996: 76-78, n. }{ }^{\circ} 28 \\
\text { Cadario, 2004: 349-351 }\end{array}$ \\
\hline 4 & $\begin{array}{l}\text { Gabii } \\
\text { (Roma, Italia) }\end{array}$ & $\begin{array}{l}\text { Museo del Louvre, en depósito en M. } \\
\text { de los Jacobinos de Auch (Francia) }\end{array}$ & $\begin{array}{l}\text { Cadario, 2004: 347-350; } \\
\text { Laube, 2006: 229, n. }{ }^{\circ} 20\end{array}$ \\
\hline 5 & $\begin{array}{l}\text { Lugdunum Conuenarum } \\
\text { (Saint-Bertrand-de-Comminges, } \\
\text { Francia) }\end{array}$ & $\begin{array}{l}\text { Museo Municipal St. Bertrand de } \\
\text { Comminges (Francia) }\end{array}$ & $\begin{array}{l}\text { Stemmer, 1978: II, 1; } \\
\text { Boschung, 2002: 138, n. } 63.3\end{array}$ \\
\hline 6 & $\begin{array}{l}\text { Olympia } \\
\text { (Olimpia, Grecia) }\end{array}$ & Museo de Olimpia (Grecia) & $\begin{array}{l}\text { Stemmer, 1978: III, 4; } \\
\text { Boschung, 2002: 101, n. } 33.4\end{array}$ \\
\hline 7 & $\begin{array}{l}\text { Roma } \\
\text { (Italia) }\end{array}$ & Palazzo Colonna de Roma (Italia) & $\begin{array}{l}\text { Gergel, 1988: 15; } \\
\text { Varner, 2004: } 72\end{array}$ \\
\hline 8 & $\begin{array}{l}\text { Rusellae } \\
\text { (Grosseto, Italia) }\end{array}$ & Museo Cívico de Grosseto (Italia) & $\begin{array}{l}\text { Stemmer, 1978: 28, II a3; } \\
\text { Boschung, 2002: 70, n. }{ }^{\circ} 20.12\end{array}$ \\
\hline 9 & $\begin{array}{l}\text { Salona } \\
\text { (Solin, Croacia) }\end{array}$ & Museo Arqueológico de Zagreb (Croacia) & $\begin{array}{l}\text { Vermeule, 1959: 39, n. }{ }^{\circ} 44 ; \\
\text { Stemmer, 1978: viI, } 5\end{array}$ \\
\hline 10 & Thessalonica (Tesalónica, Grecia) & Museo Arqueológico de Tesalónica (Grecia) & Despines et al., 2003: n. ${ }^{\circ} 261$ \\
\hline 11 & Procedencia desconocida & $\begin{array}{l}\text { Museo Británico, en depósito en } \\
\text { Hampton Court (Reino Unido) }\end{array}$ & $\begin{array}{l}\text { Smith, 1904: 156-157, n. }{ }^{\circ} 1895 \text {; } \\
\text { Cadario, 2004: 341-347 }\end{array}$ \\
\hline 12 & Procedencia desconocida & Museo de Antalya (Turquía) & $\begin{array}{l}\text { Vermeule, 1959: 58, n. }{ }^{\circ} 205 \text {; } \\
\text { Stemmer, 1978: IV, } 16\end{array}$ \\
\hline 13 & Procedencia desconocida & Museo Cívico de Mantua (Italia) & $\begin{array}{l}\text { Hekler, 1919: 228; } \\
\text { Stemmer, 1978: IV, } 13\end{array}$ \\
\hline 14 & Procedencia desconocida & $\begin{array}{l}\text { Museo de Arte, Univ. de Princeton } \\
\text { (EE. uU.) }\end{array}$ & $\begin{array}{l}\text { Gergel, 1986: 3-15; } \\
\text { Gergel, 2001: 199-201 }\end{array}$ \\
\hline 15 & Procedencia desconocida & Colección particular de Suiza & $\begin{array}{l}\text { Vermeule, 1964: 101, n. }{ }^{8} 85 \text {; } \\
\text { Stemmer, 1978: I, } 19\end{array}$ \\
\hline
\end{tabular}

FIG. 6. Tropaia en thoracathi en el mundo romano. 
reclamaban se podían erigir dos tropaia (Xen. Hell. 7. 5. 26). Desde, al menos, la primera mitad del s. V a. C., el trofeo fue evolucionando en forma y significado, hasta convertirse en un monumento duradero, que conmemoraba la victoria no sólo de un pueblo, sino también de un jefe. Con este significado, Roma adoptó desde comienzos del s. III a. C. el motivo, prefiriendo llevarlo en procesión o erigirlo en el Capitolio que levantarlo en el terreno de la contienda; desde comienzos del s. I a. C. particularmente se ubicó cerca de vías de comunicación -es el caso de los trofeos de Pompeyo en el Pirineo Oriental, el trofeo de Augusto de La Turbie, en los Alpes, y el trofeo de Trajano de Adamclisi, Rumanía-. Con el tiempo y hasta el final del Imperio, este motivo acabó por ser un símbolo abstracto de la victoria, una fórmula iconográfica cristalizada dentro del lenguaje triunfal romano. Su forma fue adquiriendo un carácter más simbólico y estereotipado. Las armas, símbolos de la guerra y de los guerreros, suspendidas en el tropaion y amontonadas a sus pies -congeries armorum-, evidenciaban el despojo -spolium- del enemigo de sus instrumentos de poder, pero no eran necesariamente copias fieles del armamento empleado en una batalla concreta, ni formaban el inventario completo de los spolia hostium (Huby, 2008: 80). Así, la 'petrificación' de las armas conquistadas supondría la creación de un repertorio estandarizado del armamento de todos los pueblos bárbaros conquistados, como símbolo del poder universal, utilizado en distintos monumentos hasta el final del Imperio (Polito, 2011: 264). Igualmente, los cautivos serían representaciones estereotipadas del bárbaro sometido e incluso, muchas veces, personificaciones de los territorios conquistados, elementos ambos que parecen presentes en el conjunto que nos ocupa. Esto no quiere decir que estas escenas fueran ficticias o inventadas; sin duda, harían alusión a hechos reales -concretos o no- tamizados por el filtro que Roma aplicaba a sus imágenes, insertas en su particular concepción del poder y del enemigo (Huby, 2008: 84), propia del carácter de expresiones de poder y de propaganda de primer orden, que adoptaría esta iconografía $-c f$. extensamente, Polito, 1998: 122-190-.

El empleo de representaciones de tropaia en thoracatos se da ya desde época de Augusto a partir de la estatua de Prima Porta (con bibliografía anterior Cadario, 2004: 251-282) y el catálogo de los paralelos iconográficamente próximos al de Los Bañales es relativamente generoso en el mundo romano (Fig. 6). Por el contrario, en Hispania no encontramos motivos con tropaion y prisioneros en la estatuaria conocida (Acuña, 1975: 35-123; Garriguet, 2001: 62-65), aunque sí ejemplares con sólo trofeos, especialmente portados por centauros como en un ejemplar de Italica hoy en el Museo Arqueológico de Sevilla (Acuña, 1975: 59-62, lám. VIII; León, 1995: 38-39) y en dos de Emerita Augusta provenientes del teatro y conservadas en el Museo Nacional de Arte Romano de Mérida (Acuña, 1975: 71-77, láms. XIV-XV; Garriguet, 2001: 11-12, n. ${ }^{\text {os }} 16$ y 17).

A pesar de todos estos paralelos son dos las estatuas estilísticamente más cercanas al ejemplar que nos ocupa. Se trata de las dos procedentes de la ciudad de Gabii (Fig. 6, n. ${ }^{\text {os }} 3$ y 4). La segunda (Fig. 6, n. ${ }^{\circ}$ ) está datada en época domicianea por la mayoría de autores e identificada probablemente como representación de Domiciano (Fig. 7). Guarda importantes similitudes con la estatua thoracata de Los Bañales de Uncastillo en varios aspectos. Así, se aprecian en ella los mismos escudos de tipo celta, los cautivos están igualmente atados al trofeo y visten también ropas germánicas como las típicas braccae. Además, también figura en la parte inferior y laterales decoración vegetal con hojas de acanto y flores muy parecidas a las que pueden verse en torno al motivo central en el ejemplar de Los Bańales, aunque en este no se dan las flores sino sólo las hojas de acanto. Nuestra coraza tiene bastantes similitudes también con la que, procedente de Gabii, se conserva en el Museo del Louvre y para la que está aceptada su identificación como Domiciano (Fig. 6, n. ${ }^{\circ} 3$ y Fig. 8) aunque para otros representaría a Trajano (Kersauson, 1996: 76). Al igual que la anterior ofrece los mismos tipos de escudos de tradición celta, los cautivos son muy cercanos estilísticamente, aunque estos no se encuentren atados al trofeo sino que exhiben las manos atadas a la espalda sobre los escudos. Además, los personajes visten las típicas braccae germánicas y parecida decoración vegetal en la parte inferior y laterales. Otro thoracatus de igual cronología e identificación sería el conservado en el Museo de Arte de la 

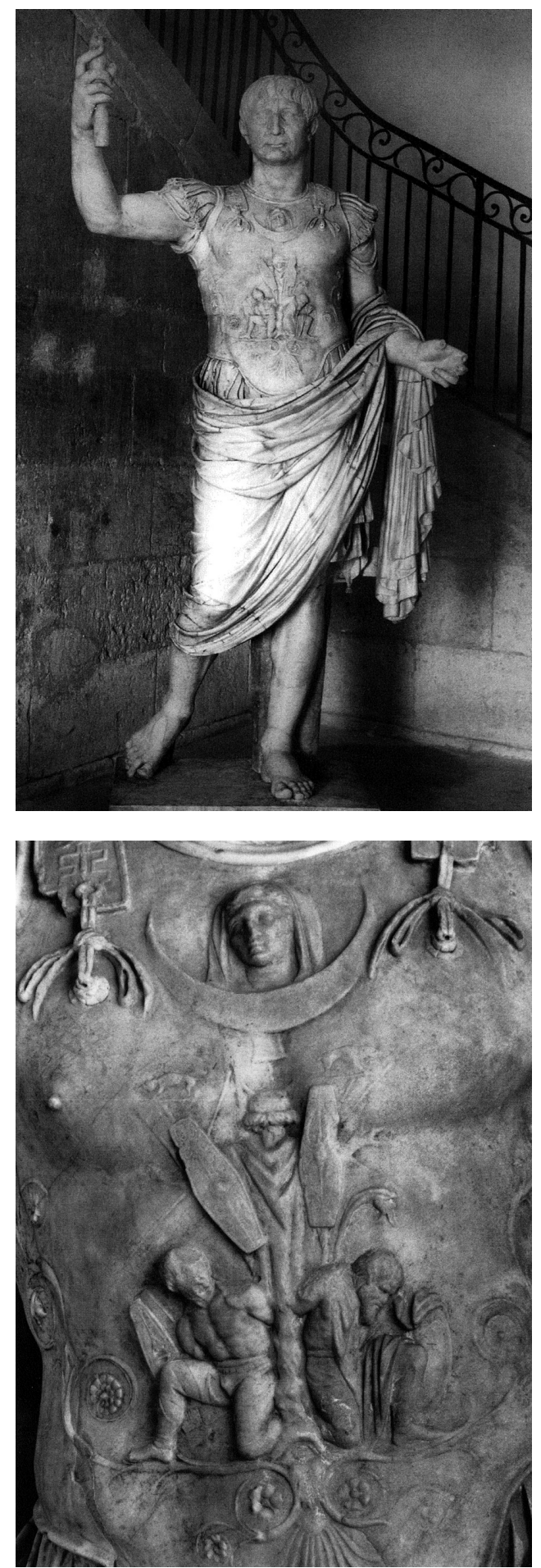

FIG. 7. Thoracatus de Gabii conservado en el Museo del Louvre, n. ${ }^{\circ}$ de inv. 1150 (Kersauson, 1996: 78) y detalle de su coraza (ibidem: 79)
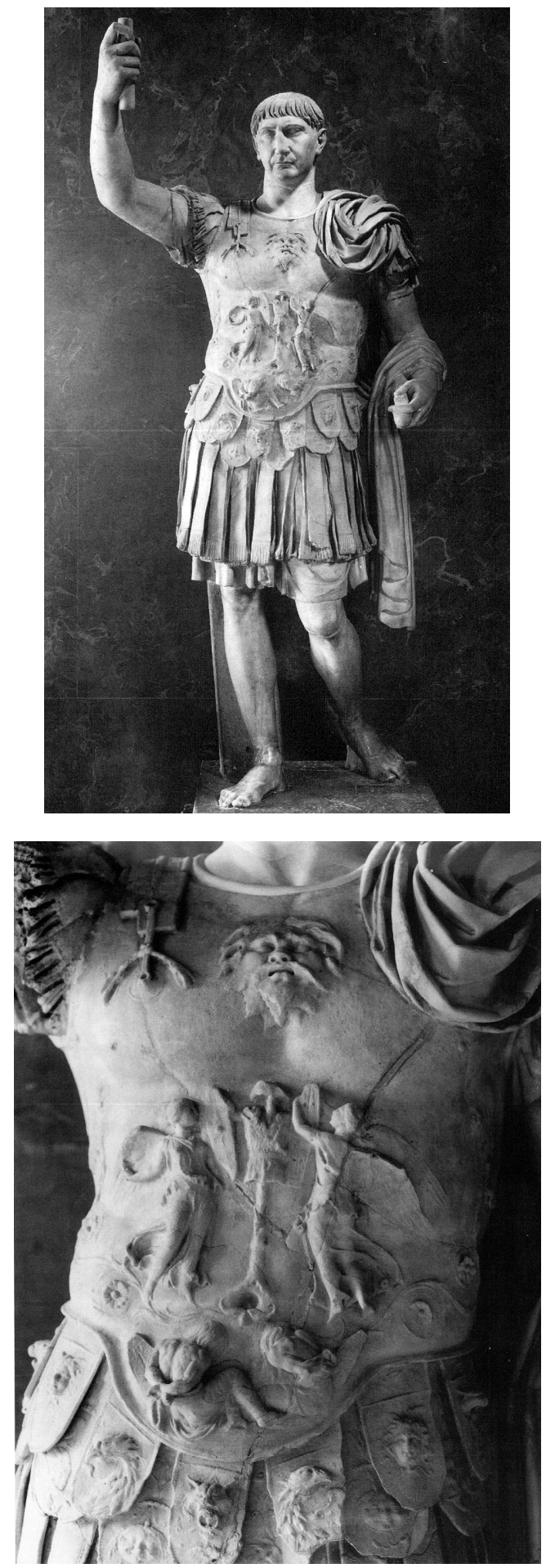

FIG. 8. Thoracatus de Gabii conservado en el Museo de los Jacobinos de Auch, n. ${ }^{\circ}$ de inv. 1154 (Kersauson, 1996: 82) y detalle de la coraza (ibidem: 83). 


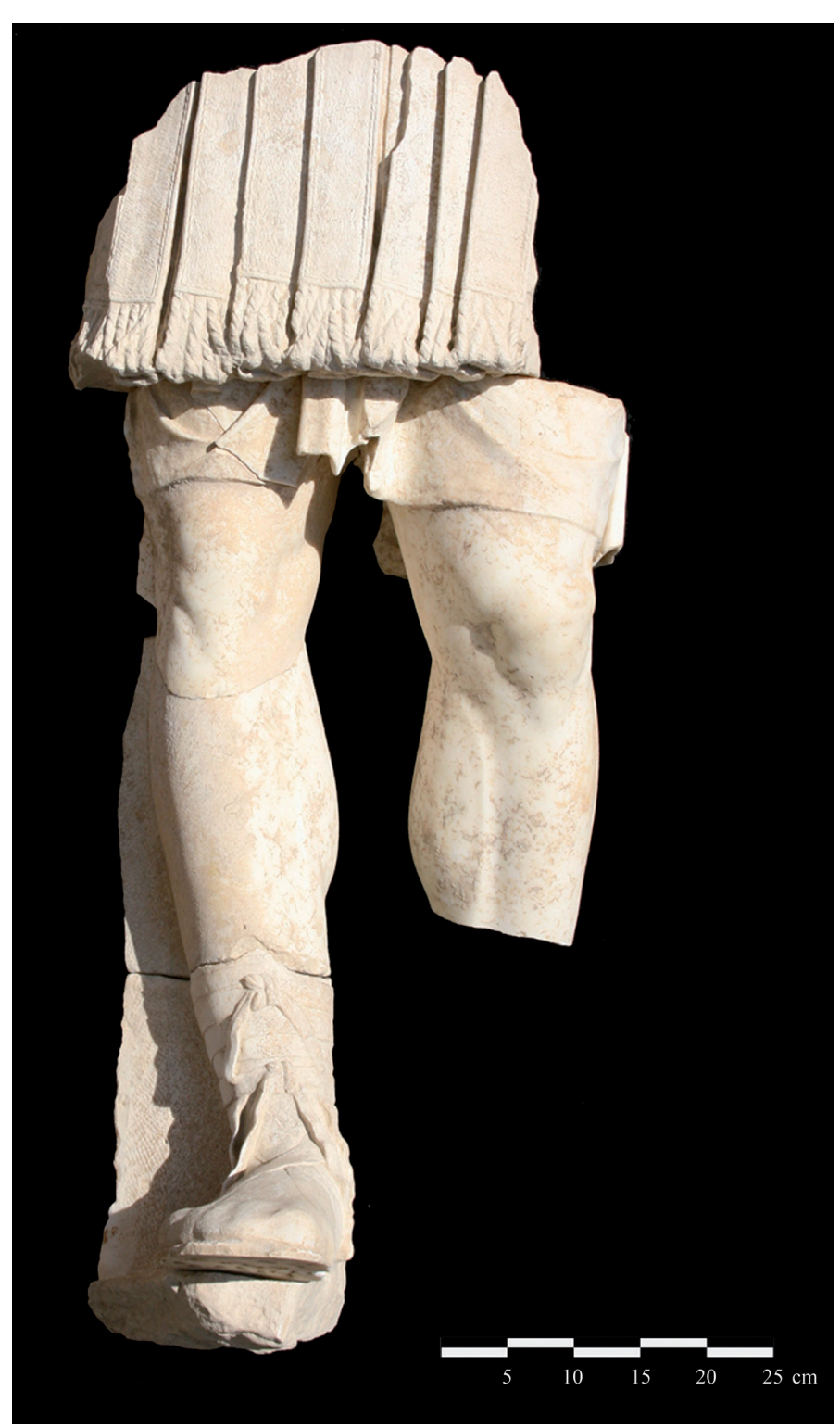

FIG. 9. Piernas, calceus y faldellin de la estatua imperial de Los Bañales (fotog. J. J. Bienes).

Universidad de Princeton (Fig. 6, n. ${ }^{\circ}$ 14). En este ejemplar, sin embargo, el prisionero se aprecia muy mal, ya que está totalmente adosado al trofeo y no está sentado sobre escudos. Sí presenta similar decoración vegetal con hojas de acanto y flores en la parte inferior y laterales. Existen otros dos ejemplares conservados hoy en los Museos Vaticanos (Fig. 6, n. ${ }^{\circ}$ 2) con cabeza de Lucio Vero y en Hampton Court en depósito por el British
Museum (Fig. 6, n. ${ }^{\circ}$ 11) que no presentan el motivo de tropaion y prisioneros como tema central pero sí como secundario en los dos laterales. Destaca el prisionero germano representado en la parte derecha con la típica vestimenta germánica que está atado al trofeo. Estos dos paralelos no presentan la decoración vegetal que sí se da, como se ha visto, en los paralelos anteriores.

Si por lo dicho hasta ahora y por los paralelos aducidos, se trata, como parece, de una representación de Domiciano y aunque en Hispania, como se ha dicho antes, no encontramos ningún paralelo con tropaion y cautivos, con similar cronología e identificación en el solar hispano tendríamos la estatua thoracata del foro de Segobriga (Noguera, Abascal y Cebrián, 2008: 309314 y Noguera, 2012: 184-188) que si bien es datado de forma habitual como de época neroniana (Noguera, 2012: 184-188) hay autores que le dan una cronología flavia y lo identifican con el emperador Domiciano (Ojeda, 2008: 323-328).

\subsection{Calceus, piernas y faldellin (Fig. 9)}

a) Ficha técnica

Material: mármol blanco de Carrara ( $c f$. Anexo).

Dimensiones: alt. máx.: $90 \mathrm{~cm}$; anch. máx: $43,50 \mathrm{~cm}$ y alt. rodilla a planta $54 \mathrm{~cm}$ (calceus y piernas); alt. máx.: $23 \mathrm{~cm}$; anch. máx: $36 \mathrm{~cm}$; gr. máx.: $10,5 \mathrm{~cm}$ y anch. launae $4,5 \mathrm{~cm}$ (faldellín).

Conservación: conjunto muy fragmentado en 8 fragmentos encajables entre sí al que se le une el faldellín. Lo preservado de las piernas y el calceus corresponde a parte del colobium, sobre el que iría el faldellín de launae. El pie izquierdo falta. En relación al faldellín la conservación es también buena aunque no se ha preservado la totalidad del mismo que, además, tiene fracturas en la parte alta y en los dos laterales por lo que sus dimensiones totales serían algo mayores.

b) Descripción, análisis iconográfico, paralelos e identificación: analizando la postura de los 
fragmentos descritos, con la pierna izquierda más flexionada hacia detrás y el peso del cuerpo cayendo sobre la pierna derecha es evidente que el conjunto se elaboró siguiendo el ejemplo del Augusto de Prima Porta (Cadario, 2004: 251282) y en una postura semejante a otras estatuas thoracatae de época domicianea antes citadas (Fig. 6, n. ${ }^{\text {s }}$ 2, 3, 11 y Fig. 8). En el ejemplar de Los Bañales destacan su ejecución técnica y las calidades del acabado que se traducen en mostrar la anatomía de los dedos del pie diestro bajo la piel del calceus. Las lazadas inferiores del calceus caen hasta casi el final del pie. Hay numerosos paralelos para este tipo de calceus, de carácter senatorial, por ejemplo, lo portan Augusto y los flamines en el Ara Pacis (Goldman, 2001: 102, 125, 119-120), la estatua de Augusto de la Via Labicana, la de Tiberio en bronce de Herculano, la de Calígula proveniente de Gortina o la de Claudio procedente de Velleia entre otras (Goette, 1988: 452-453). En cuanto a su uso en estatuas thoracatas, destaca una identificada como Tito, de Olympia (Goette, 1988: 453). En la Península Ibérica su paralelo más cercano es un calceus patricius proveniente de Carthago Nova interpretado, también, como vinculado a una representación imperial (Noguera, 2003: 50-51).

Por su parte, el faldellín está compuesto por 8 launae en una única hilera que muestra ribete en los laterales y remata con cordoncillos. Se aprecia el impulso de las launae hacia el lado derecho, algo propio de las estatuas imperiales de época flavia (Ojeda, 2008: 324) y otro argumento a favor de la filiación cronológica domicianea que proponemos para este conjunto.

\subsection{Pteryks (Fig. 10)}

a) Ficha técnica

Material: mármol blanco de Carrara ( $c f$. Anexo).

Dimensiones: alt. máx.: $7,5 \mathrm{~cm}$; anch. máx: 6 cm; gr. máx.: $0,9 \mathrm{~cm}$.

Conservación: fragmentaria, algo más de la mitad aunque con un acusado corte en la parte izquierda que ha dañado al motivo central.

b) Descripción, análisis iconográfico, paralelos e identificación: el lambrequín representa a una Gorgona sonriente de la que se conserva sólo la

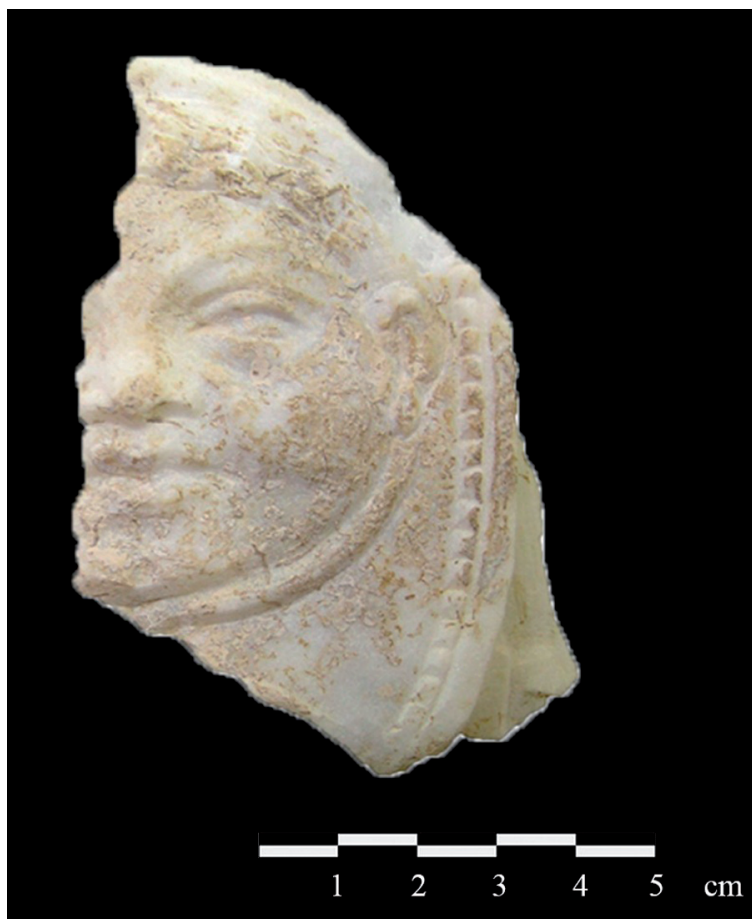

FIG. 10. Pteryks con representación de Gorgona (fotog. H. Royo).

mitad derecha de la cara y su parte central. La Gorgona es muy habitual como motivo decorativo en los thoracati (Stemmer, 1978: 162) y, en este caso, se trataría de una Schöner-typus, de tradición claramente helenística (Stemmer, 1977: 162 G; Floren, 1977: 177-217). En Hispania, hay 3 paralelos que se asemejan mucho al que nos ocupa: las presentes en la pieza thoracata del foro de Segobriga (Noguera, 2012: 186), en otro de Italica (León, 1995: 38-39, n.o 3) y uno más de Torreparedones (Márquez, 2013: 25).

\subsection{Hombro (Fig. 11)}

a) Ficha técnica

Material: mármol blanco de Carrara ( $c f$. Anexo).

Dimensiones: alt. máx.: $21 \mathrm{~cm}$; anch. máx: $16,50 \mathrm{~cm}$; gr. máx.: $11 \mathrm{~cm}$.

Conservación: buena, pero se trata sólo de un fragmento del hombro. Se aprecia un corte oblicuo en la parte final de las launae y un segundo corte en el comienzo del brazo desnudo. 


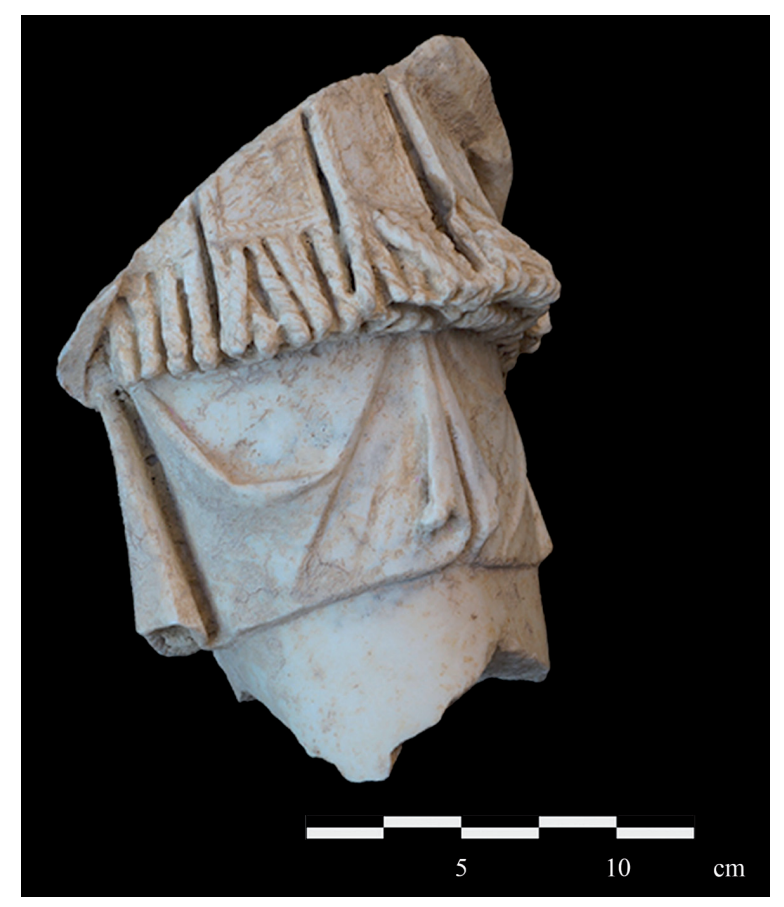

FIG. 11. Hombro probablemente adscribible a la estatua thoracata de Los Bañales (fotog. Paleorama).

b) Descripción, análisis iconográfico, paralelos e identificación: se conserva parte de las launae del hombro, por debajo sobresale un trozo del colobium al igual que en las piernas. Es probable que corresponda a un fragmento del hombro izquierdo de la estatua, ya que el derecho suele mostrarse levantado en posición de adlocutio. El colobium al estar levantado -al igual que ocurre en los dos paralelos procedentes de Gabii (Fig. 6, n. ${ }^{\text {os }}$ 3 y 4) - tendría dobleces por la postura del brazo.

\section{5 y 6. Otros fragmentos}

Aunque es probable que los fragmentos pertenecieran al thoracato objeto de estudio existe cierta duda razonable al respecto. Los dos fragmentos, en cualquier caso, están labrados en el mismo tipo de mármol que el resto del conjunto. El n. ${ }^{\circ} 5$ además de a una pieza thoracata podría pertenecer a una estatua tipo Hüftmantel o a otro tipo de representación con manto como en algunas figuraciones de dioses. Esta hipótesis está también apoyada en la presencia de otros fragmentos escultóricos de representaciones desnudas encontrados en la misma campaña y en el mismo espacio. El n.o 6 podría pertenecer a cualquier otro tipo de representación, pero el común lugar de aparición, su labra delicada y el tipo de mármol permiten relacionarlo con la pieza thoracata que nos ocupa.

\subsection{Paludamentum (Fig. 12)}

a) Ficha técnica

Material: mármol blanco de Carrara ( $c f$. Anexo).

Dimensiones: alt. máx.: $24 \mathrm{~cm}$; anch. máx: 10 cm; gr. máx.: $17 \mathrm{~cm}$.

Conservación: fragmento del paludamentum de una estatua, con una fractura casi horizontal que hace que sólo se conserve la parte final del mismo. Se aprecian algunas fracturas en la parte inferior, de caída, de los pliegues.

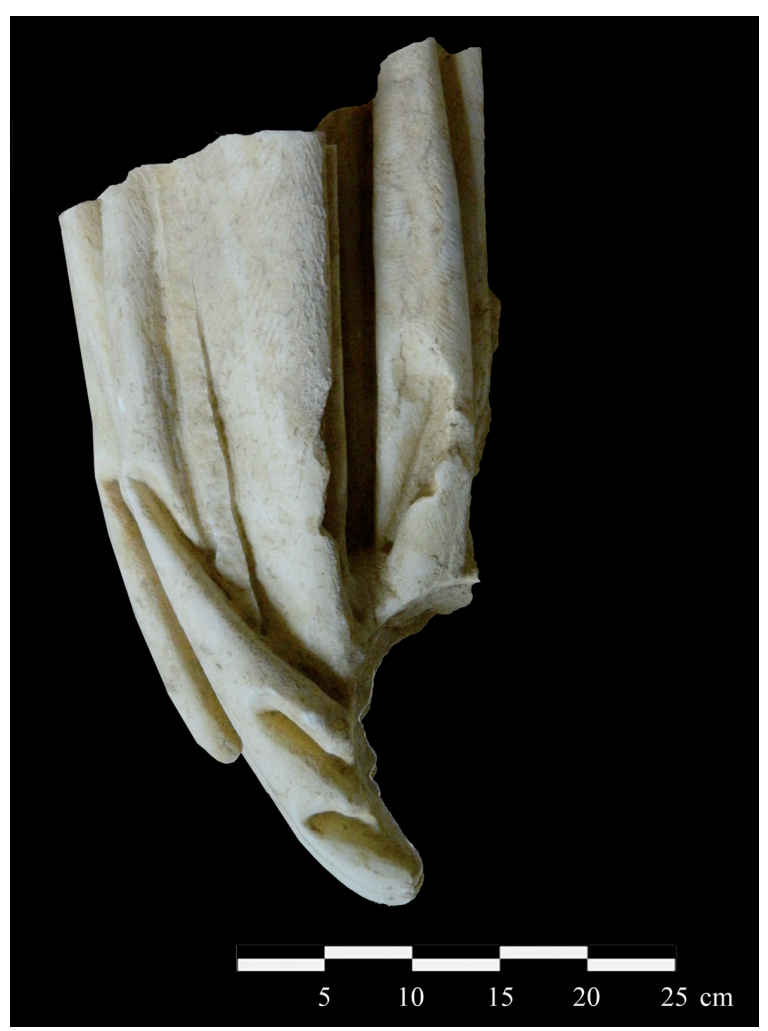

FIG. 12. Paludamentum posiblemente vinculado a la estatua de Los Bañales (fotog. L. Romero). 
b) Descripción, análisis iconográfico, paralelos e identificación: se trata de la parte final de los pliegues del paludamentum que caería desde el hombro. Tiene como paralelo más cercano en la forma de caída la thoracata de Domiciano con cabeza de Trajano del Museo del Louvre (Fig. 6, n. $\left.{ }^{\circ} 3\right)$.

\subsection{Mano (Fig. 13)}

a) Ficha técnica

Material: mármol blanco de Carrara ( $c f$. Anexo).

Dimensiones: alt. máx.: $16 \mathrm{~cm}$; anch. máx: 12 $\mathrm{cm}$; gr. máx.: $5,5 \mathrm{~cm}$.

Conservación: buena, aunque con fractura a la altura de la muñeca, habiendo perdido 3 falanges: corazón, anular y meñique.

b) Descripción, análisis iconográfico, paralelos e identificación: la labra del fragmento es muy detallista y depurada. Destaca el detalle de las venas marcadas y las arrugas de las falanges. Esas calidades en el acabado, que también se aprecian en la extraordinaria ejecución del calceus y de los motivos iconográficos de la coraza, podrían alimentar la idea de formar parte de la misma estatua o, acaso, del mismo programa iconográfico. Se trataría de la mano derecha de la estatua, aunque como se ha comentado antes no es seguro que perteneciera a la estatua thoracata que aquí estudiamos.

\section{Identificación de la estatua, contexto histórico y topográfico (Fig. 14)}

La estatua es de tamaño algo mayor que el natural y pertenecería al tipo de loricatos clasicistas con pteryges mixtos, modelo de larga historia que acabó por convertirse en el modelo de estatua militar por excelencia (Cadario, 2004: 13-14).

Tenemos varias pruebas para su identificación: los paralelos anteriormente citados para la coraza, el calceus y el faldellín, monedas de Domiciano con similar iconografía y motivos estilísticos internos de la propia pieza. Los paralelos más cercanos, como se ha dicho, serían las dos estatuas de

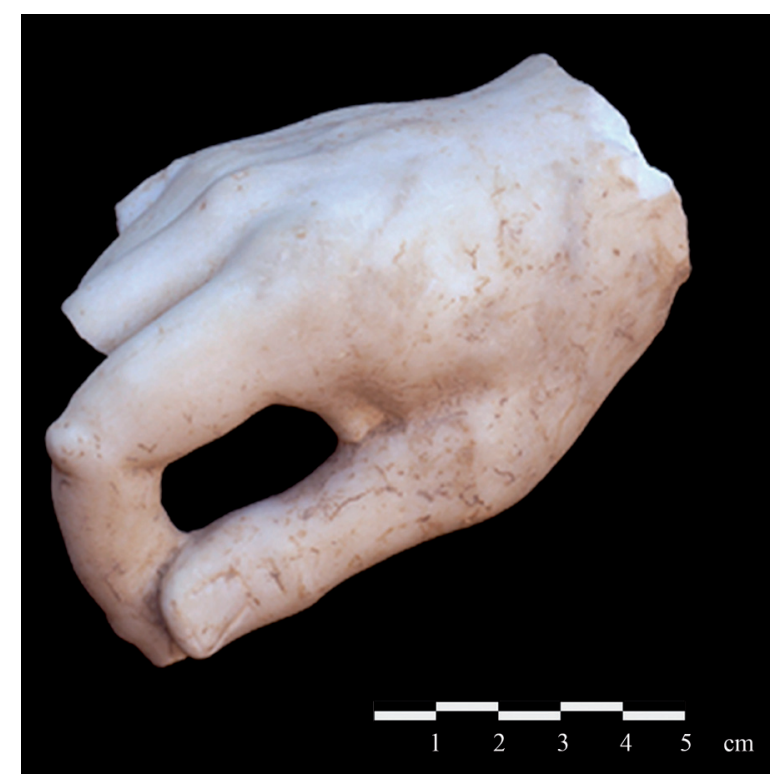

FIG. 13. Mano perteneciente a la estatua imperial (fotog. Paleorama).

Gabii (Fig. 6, n. ${ }^{\text {os }} 3$ y 4 ) que muy probablemente representen al emperador Domiciano.

Además, existe una serie de monedas acuñadas por Domiciano en las que encontramos algunos indicios iconográficos de interés. En una serie, por ejemplo, se representan tropaia con cautivos y escudos similares a los representados en la pieza thoracata de Los Bañales (RIC 252, 278 a, 278 b y 341) (Fig. 15). En dicho tipo aparece a la izquierda una cautiva sentada sobre escudos alargados con refuerzo central (scuta) y en actitud reposada, en el centro está el tropaion-también con escudos- y a la derecha hay un cautivo con braccae germánicas de idéntica factura al de nuestro thoracato y con túnica sobre el cuerpo, en el suelo otro escudo alargado y un casco. En otra serie de áureos se muestra a una personificación de Germania (RIC, n. ${ }^{\text {os }}$ 69, 72, 77, 83, 103, 111, 127, 164, 184, 202) (Fig. 16). Tienen importantes concomitancias con la figura femenina en actitud de reposo presente en la parte izquierda de la coraza (Fig. 5) que, en razón de ello, podría ser una representación de Germania. Ambas representaciones están en actitud reposada sobre un escudo alargado y portan además las típicas braccae germanas. Además, en el Augusto de Prima Porta tenemos representaciones alegóricas 


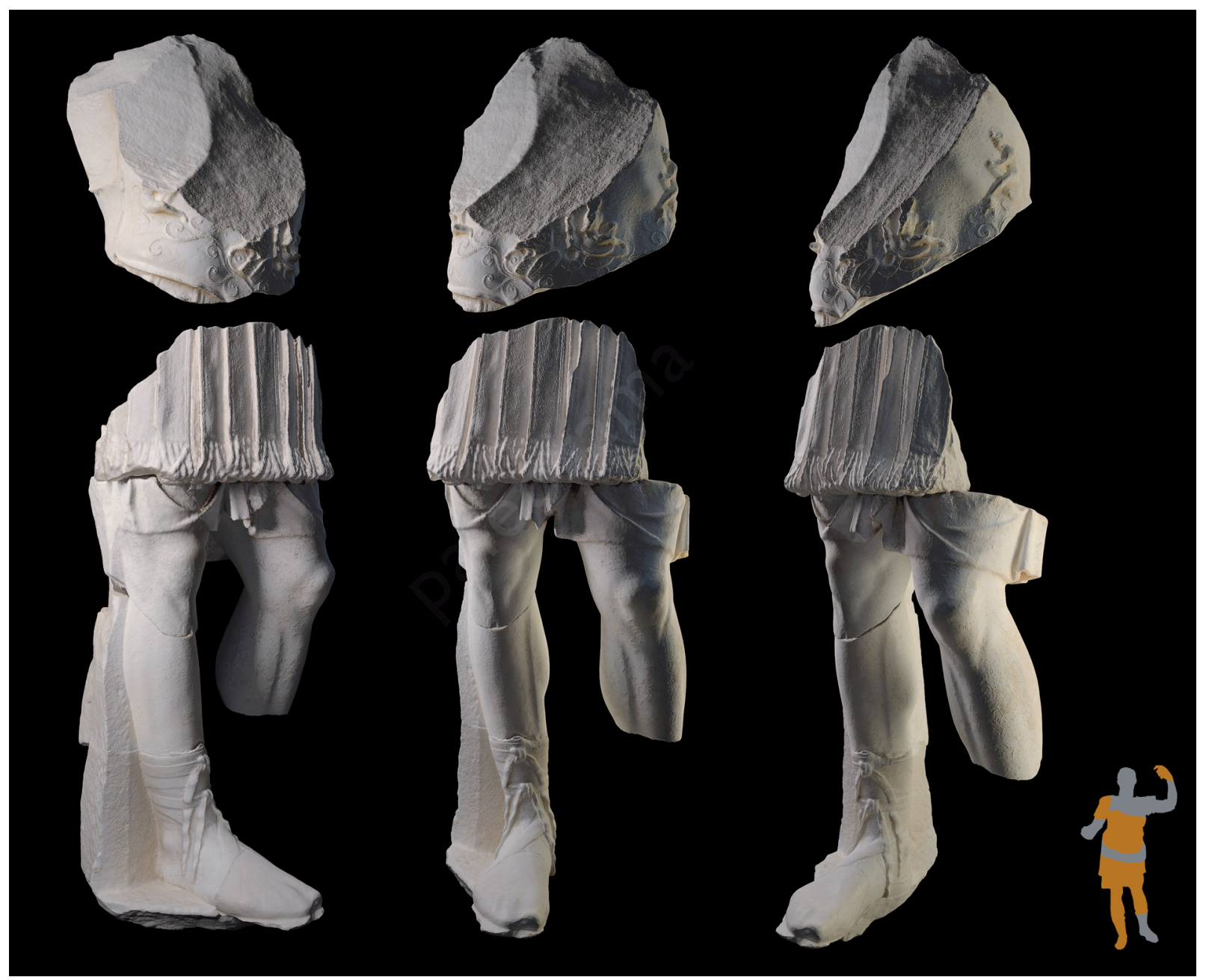

FIG. 14. Restitución, por fotogrametría 3D, de la estatua thoracata de Los Bañales (fotog. Paleorama).

de Galia e Hispania (Cadario, 2004: 270-272), por lo que no es descabellada esta hipótesis de identificación. La misma representación se da también en una serie de denarios de la misma época (RIC, n. ${ }^{\circ}$ 66a). Hay otra serie que muestra a la Victoria Augusta junto a un trofeo con escudos también similares (RIC, n. ${ }^{\text {os }} 268,296,305$, 330 a y b, 339). En base a esta interpretación, la figura derecha del thoracato, podría reinterpretarse como la personificación de otra provincia en actitud reposada y en posición simétrica a la Germania, al igual que en el Augusto de Prima Porta. Sin embargo, lo fragmentario de la representación nos impide confirmar dicha hipótesis y ofrecer una adecuada interpretación sobre la provincia de que se trata.

Estilísticamente la pieza también parece de época flavia. Además del motivo de tropaion y cautivos similar estilísticamente a los dos ejemplares de Gabii, se constata el impulso de las launae hacia el lado derecho en el faldellín, debido a la presión hacia el lado izquierdo de la cadera así como recuerdan a motivos de idéntica cronología los motivos vegetales que la coraza exhibe, rasgos que parecen característicos de estatuas de época flavia (Ojeda, 2008: 324).

Con las siguientes pruebas proponemos una cronología domicianea para el thoracato de Los 


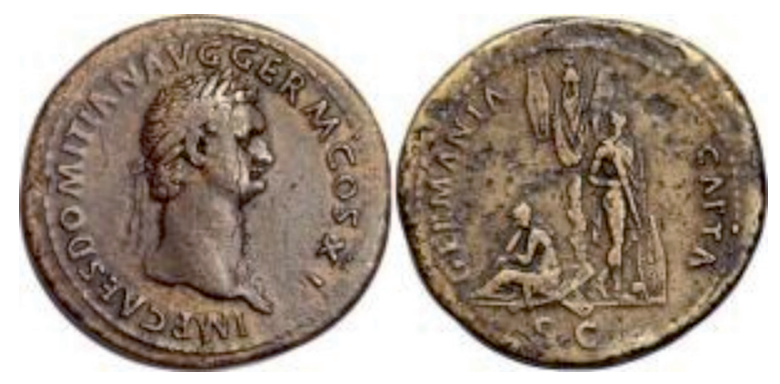

FIG. 15. Serie monetal domicianea con tropaion, cautivos y escudos (http://www.acsearch.info/images/2_m/ 17306.jpg; acceso 14/04/2014).

Bañales, que muy probablemente represente al propio Domiciano tras su triunfo en Germania sobre los Catos en el año $83 \mathrm{~d}$. C. Se trataría de un nuevo modelo de representación del emperador con motivo de tropaion y cautivos, ya que hasta ahora se conocían dos modelos. El primero representando un trofeo central al que aparecen atados dos prisioneros y que se correspondería con las dos esculturas provenientes de Gabii y que conmemoran la victoria sobre los Catos del año 83 d. C. (Fig. 6, n. ${ }^{\text {os }} 3$ y 4) -estilística y conceptualmente próximo al ejemplar de Los Bañales- y el segundo modelo con un motivo central con la Victoria Augusta y dos motivos laterales con sendos trofeos que representan las victorias sobre germanos y dacios cuyos modelos conocidos son uno de los Museos Vaticanos y hoy con cabeza de Lucio Vero (Fig. 6, n.o 2) y otro perteneciente al British Museum (Fig. 6, n.o 11).

Sin perjuicio de que el contexto de procedencia de los materiales analizados sea secundario y pudieran almacenarse en él fragmentos escultóricos de todo el aparato iconográfico del foro de la ciudad romana, no resulta descabellado ubicar la posición primaria de la estatua thoracata en el cercano recinto de representación del pórtico occidental del foro de Los Bañales dedicado a la Victoria Aug (usti) ${ }^{6}$. La Victoria es la expresión divinizada del poder militar de los emperadores (Perea, 2007: 225) y qué mejor manera de expresar esa idea que coronando la inscripción con un thoracato del emperador vencedor de los Catos.

\footnotetext{
${ }^{6}$ Jordán y Andreu: op. cit. n. 3.
}

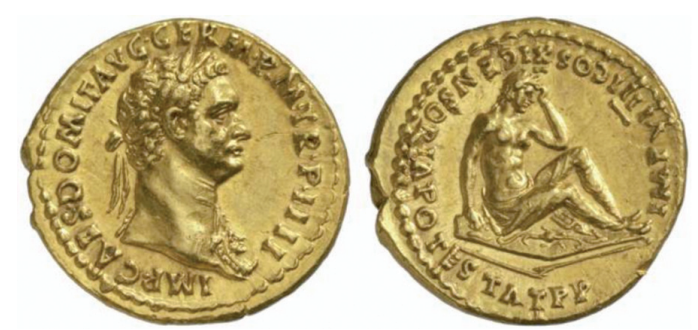

FIG. 16. Personificación de Germania en un áureo de Domiciano (http://i926.photobucket.com/albums/ ad102/Zannanza/TRAJAN/domitian-germania_ zpsefd76f8f.jpg; acceso 14/04/2014).

Además tenemos como prueba la serie monetal (RIC, n. ${ }^{\text {os }} 268,296,305,330^{\mathrm{a}}$ y b y 339 ) anteriormente citada en donde se muestra la relación emperador/Victoria Augusta/trofeo. La erección de este thoracato en ese recinto -de carácter autorrepresentativo en tanto que promovido por M. Fabius Nouus y Porcia Fauentina- ${ }^{7}$ sería un signo de agradecimiento de la élite local a la casa imperial que generó la promoción jurídica de la ciudad en un fenómeno ya conocido en otros recintos dedicados a la Victoria Augusta en Hispania (Perea, 2007: 229-232). La propia paleografía del conjunto epigráfico podría abonar aun más esta hipótesis de interpretación pues parece que debería ubicarse cronológicamente entre Tiberio y Trajano.

Con la damnatio de Domiciano y a pesar de que en Hispania sabemos que esta no se aplicó con carácter general (Stylow, 1986: 289), es probable que el retrato de la escultura fuera reelaborado en uno de los emperadores ulpioaelios en un fenómeno sobradamente repetido a lo largo del imperio (Varner, 2004: 111-135) y con ejemplos hispanos trajaneos como los de Acci, Aeminium, Baelo Claudia y Regina (Ojeda, 2010: 270). Sólo posteriores hallazgos en esta apasionante unidad estratigráfica y nuestro avance en el conocimiento del foro de la ciudad romana de Los Bañales -que nos depara, sin duda, aún, no imaginadas sorpresas- podrá confirmar o desmentir lo que se ha expuesto en este trabajo.

\footnotetext{
${ }^{7}$ Jordán y Andreu: op. cit. n. 3.
} 


\section{Bibliografía}

ACUÑA, P. (1975): Esculturas militares romanas de España y Portugal I: Las esculturas thoracatas. Roma.

Andreu, J. (2004-2005): "Algunas consideraciones sobre las ciudades romanas del territorio vascón y su proceso de monumentalización", Espacio, Tiempo y Forma. Serie 2. Historia Antigua, 17-18, pp. 251-299.

ANDReu, J. (2011): "La ciudad romana de Los Bañales en las fuentes históricas". En La ciudad romana de Los Bañales (Uncastillo, Zaragoza): entre la historia, la arqueología y la historiografía. Caesaraugusta, 82. Zaragoza, pp. 19-101.

Betalli, M. (2009): "I trofeo sui campi di battaglia nel mondo Greco", Mélanges de l'École Française de Rome. Antiquité, 121 (2), pp. 363-371.

BoschunG, D. (2002): Gens Augusta. Untersuchungen zu Aufstellung, Wirkung und Bedeutung der Statuengruppen des julisch-claudischen Kaiserhauses. Mainz am Rhein.

CADARIO, M. (2004): La corazza di Alessandro: Loricati di tipo ellenistico dal IV secolo a.C. al II d.C. Milano.

Caprino, C.; Colini, A. M.; Gatti, G.; Pallottino, M. y Romanelli, P. (1955): La colonna di Marco Aurelio. Roma.

Castellvi, G. (2003): "Le captif au trophée: dévelopment d'une thème iconographique dans l'art romain (IIe s. av. J.-C.-IVe s. ap. J. C.)". En Peuples et territoires en Gaule Méditerranéene. Hommage à Guy Barruol. Paris, pp. 451-462.

De Angelis, M. (2002): Scultura antica in Palazzo Altemps: Museo Nazionale Romano. Milano.

Despines, G.; Stefanidou-Tiveriou, T. y Voutiras,

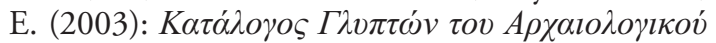

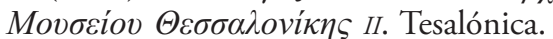

ESPAÑA, S. (2011): "Propaganda, identidad, ideología y perspectiva en la escena de batalla del sarcófago de Portonaccio", ArqueoUCA, 1, pp. 93-106.

Floren, J. (1977): Studien zur typologie des Gorgoneion. Aschendorff.

GABALDÓn, M. ${ }^{a}$ M. (2005): Rituales de armas y de victoria. Lugares de culto y armamento en el mundo griego. Oxford.

GARRIGUET, J. A. (2001): La imagen del poder imperial en Hispania. Tipos estatuarios. Corpus Signorum Imperii Romani, España, vol. II, fasc.1. Murcia.

GergeL, R. A. (1986): "An Allegory of Imperial Victory on a Cuirassed Statue of Domitian", Record of the Art Museum, Princeton University, 45 (1), pp. 2-15. http://dx.doi.org/10.2307/3774652

Gergel, R. A. (1988): "A Late Flavian Cuirassed Torso in the J. Paul Getty Museum", The J. Paul Getty Museum Journal, 16, pp. 5-24.
Gergel, R. A. (2001): "Costume as geographic indicator: barbarians and prisoners on cuirassed breastplates". En SEBesta, J. L. y Bonfante, L. (eds.): The world of Roman costume. Madison, pp. 191-209.

Goette, H. R. (1988): "Mulleus - Embas - Calceus. Ikonographische Studien zu römischem Schuhwerk", Jahrbuch des Deutschen Archäologischen Instituts, 103, pp. 401-464.

Goldman, N. (2001): "Roman Footwear". En Sebesta, J. L. y Bonfante, L. (eds.): The world of Roman costume. Madison, pp. 101-129.

Hekler, A. (1919): "Beiträge zur Geschichte der antiken Panzerstatuen", Jahreshefte des Österreichischen Archäologischen Institutes, 19-20, pp. 190-241.

HölsChER, T. (2006): "The transformation of Victory into power: from event to structure". En DiLON, S. y WeLCH, K. E. (eds.): Representations of War in Ancient Rome. Cambridge, pp. 27-48.

Huby, C. (2008): "Réalité et representation dans l'art romain. L'exemple des trophées aus captifs", Méthodes et Interdisciplinarité en Sciences Humaines, 1, pp. 69-87.

Kersauson, K. (1996): Catalogue des portraits romains II. De l'année de la guerre civile (68-69 après J.C.) à la fin de l'empire. Paris.

LaubE, I. (2006): Thorakophoroi. Gestalt und Semantik des Brustpanzers in der Darstellung des 4. Bis 1. Jhs. v. Chr. Leidorf.

LEJARS, T. (2011): "L'armament celtique en fer". En Giardino, C. (ed.): Archeometallurgia: Dalla conoscenza alla fruizione. Bari, pp. 133-147.

LEÓN, P. (1995): Esculturas romanas de Italica. Sevilla.

MÁrquez, C. (2013): "La función de la escultura en una ciudad romana: el ejemplo de Torreparedones (Baena, Córdoba)", Itvci, 1, pp. 20-28.

Mattingly, H. y Sydenham, E. A. (1926): Roman Imperial Coinage, vol. 2: Vespasian to Hadrian. London.

Moreno, S. (2007): "Contexto y funcionalidad de las representaciones escultóricas pétreas de Pollentia", Arqueología y Territorio, 4, pp. 87-106.

Noguera, J. M. (2003): “Arx Asdrubalis. Historia y Arqueología de un espacio privilegiado de Cartagena en la Antigüedad". En Noguera, J. M. (ed.): Arx Asdrubalis. Arqueología del Cerro del Molinete (Cartagena). Murcia, vol. I, pp. 13-74.

Noguera, J. M. (2012): Segobriga (provincia de Cuen$c a$, Hispania Citerior), Corpus Signorum Imperii Romani-España, vol. I, 4. Tarragona.

Noguera, J. M.; Abascal, J. M. y Cebrián, R. (2008): "El programa escultórico del foro de Segobriga". En Noguera, J. M. y Conde, E. 
(eds.): Escultura romana en Hispania V. Murcia, pp. 283-343.

OJEDA, D. (2008): "Un torso militar de época domicianea en Segobriga", SPAL, 17, pp. 323-328. http://dx.doi.org/10.12795/spal.2008.i17.14

OJEDA, D. (2010): "Las representaciones estatuarias y los retratos de Trajano en Hispania: una revisión", Archivo Español de Arqueología, 83, pp. 267-280. http://dx.doi.org/10.3989/aespa.083.010.015

OJedA, D. (2011): Trajano y Adriano. Tipología estatuaria. Sevilla.

PARdyová, M. (2004): "Le sarcophage de Portonaccio et la composition de son décor", Graeco-Latina Brunensia, 9, pp. 55-76.

Perea, S. (2007): "El culto a la Victoria Augusta en Roma y en la Hispania altoimperial". En HERNÁNDEZ GUERRA, L. (ed.): El mundo religioso hispano bajo el Imperio Romano: pervivencias y cambios. Valladolid, pp. 221-235.

PiCARD, G. C. (1957): Les trophées romains. Contributions à l'histoire de la religion et de l'arc triumphal de Rome. Paris.

Polito, E. (1998): Fulgentibus armis. Introduzione allo studio dei fregi d'armi antichi. Roma.

Polito, E. (2011): "La pietrificazione delle armi conquistate". En Masseria, C. y Loscalzo, D. (eds.):
Miti di guerra, riti di pace. La guerra e la pace: un confronto interdisciplinare. Bari, pp. 259-266.

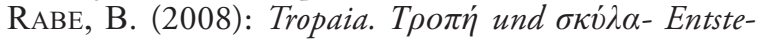
hung, Funktion und Bedeutung des griechischen Tropaions. Leidorf.

RAPIN, A. (1999): "L'armement celtique en Europe. Chronologie de son évolution technologique du ve au Ier. s. av. J.-C.”, Gladius, 19, pp. 33-68. http://dx.doi.org/10.3989/gladius.1999.13

Smith, A. H. (1904): A catalogue of sculpture in the Department of Greek and Roman Antiquities, British Museum. London, 3 vols.

Stemmer, K. (1978): Untersuchungen zur Typologie, Chronologie und Ikonographie der Panzerstatuen. Berlin.

STylow, A. U. (1986): "Apuntes sobre epigrafía de época flavia en Hispania”, Gerión, 4, pp. 285-312.

VARNER, E. R. (2004): Mutilation and Transformation: Damnatio Memoriae and Roman Imperial Portraiture. Leiden.

Vermeule, C. C. (1959): "Hellenistic and Roman cuirassed statues", Berytus, 13, pp. 1-82.

Vermeule, C. C. (1964): "Hellenistic and Roman cuirassed statues: a supplement", Berytus, 15, pp. 95-110. 


\section{ANEXO}

\section{ESTUDIO ARQUEOMÉTRICO DE UN CONJUNTO DE FRAGMENTOS DEL THORACATVS DE LOS BAÑALES (UNCASTILLO, ESPAÑA)}

\section{Archeometric study of a set of fragments of a Roman thoracatus found in Los Bañales (Uncastillo, Spain)}

Hernando Royo Plumed y Ana de Mesa Gárate

Unitat d'Estudis Arqueomètrics. Institut Català d'Arqueologia Clàssica. Tarragona

\section{Introducción}

En julio de 2013 se produjo el hallazgo de un conjunto de 40 fragmentos escultóricos en el foro de la ciudad romana de Los Bañales (Uncastillo, Zaragoza), la mayoría de ellos en mármol blanco de diversas procedencias y características que se relacionan con otros fragmentos localizados próximos y en equivalencia estratigráfica, en anteriores campañas ${ }^{1}$. Varios de estos fragmentos han sido asignados a una escultura thoracata imperial. El objetivo de este estudio es determinar la procedencia del mármol y valorar si los trozos inconexos podrían pertenecer a una misma escultura mediante análisis arqueométricos del material de los 6 fragmentos de mármol seleccionados y que son presentados en el estudio del que éste hace de anexo. Estos fragmentos se corresponden con diversas partes de una estatua (Fig. 1): coraza (n. ${ }^{\circ}$ 1/LBÑ1005), piernas (n. ${ }^{\circ}$ 2/LBÑ 1002), faldellín (n. ${ }^{\circ}$ 3/LBÑ 1003), hombro (n. ${ }^{\circ}$ 5/LBÑ 1004), paludamentum (n. ${ }^{\circ}$ 6/LBÑ 1007) y mano (n. ${ }^{\circ}$ 7/LBÑ 1006).

${ }^{1}$ Andreu, J.; Lapuente, P.; Royo, H. y Brilli, M.: "Imported marbles from the Roman cities of Cinco Villas de Aragón (Zaragoza), North of Hispania Citerior". En Proceedings $X^{\text {th }}$ ASMOSIA Conference (Roma 2012). Roma, en prensa.

\section{Metodología analítica}

El análisis comprende el estudio petrográfico macroscópico sin alterar la muestra, realizado mediante una lupa binocular ZEISS Stemi 2000, y microscópico, efectuado en un microscopio óptico de polarización -con nícoles paralelos y nícoles cruzados- Nikon ECLIPSE 50iPOL, siendo necesario, para ello, elaborar una lámina delgada -realizada en el Laboratorio de Preparación de Láminas Delgadas del Dpto. de Geología de la Univ. Autónoma de Barcelona- sin cubrir, con un grosor de $30 \mu \mathrm{m}$ y teñida parcialmente mediante rojo de Alizarina para reconocer la naturaleza de los minerales carbonatados presentes -discriminación entre calcita y dolomita-, prestando una especial atención a los criterios composicionales -mineralogía-, texturales y granulométricos (Lazzarini et al., 1980). El estudio se ha completado con el análisis de catodoluminiscencia-CL utilizando un dispositivo CITL CL8200 Mk-5-1 acoplado al microscopio que permite observar la respuesta luminiscente de la muestra al ser excitada mediante un haz de electrones (Barbin et al., 1992). Ambos análisis fueron realizados en el laboratorio de la Unitat d'Estudis Arqueomètrics del ICAC, Tarragona.

Este estudio se combina con el análisis de isótopos estables de $\mathrm{C}$ y $\mathrm{O}$, realizado en el laboratorio 

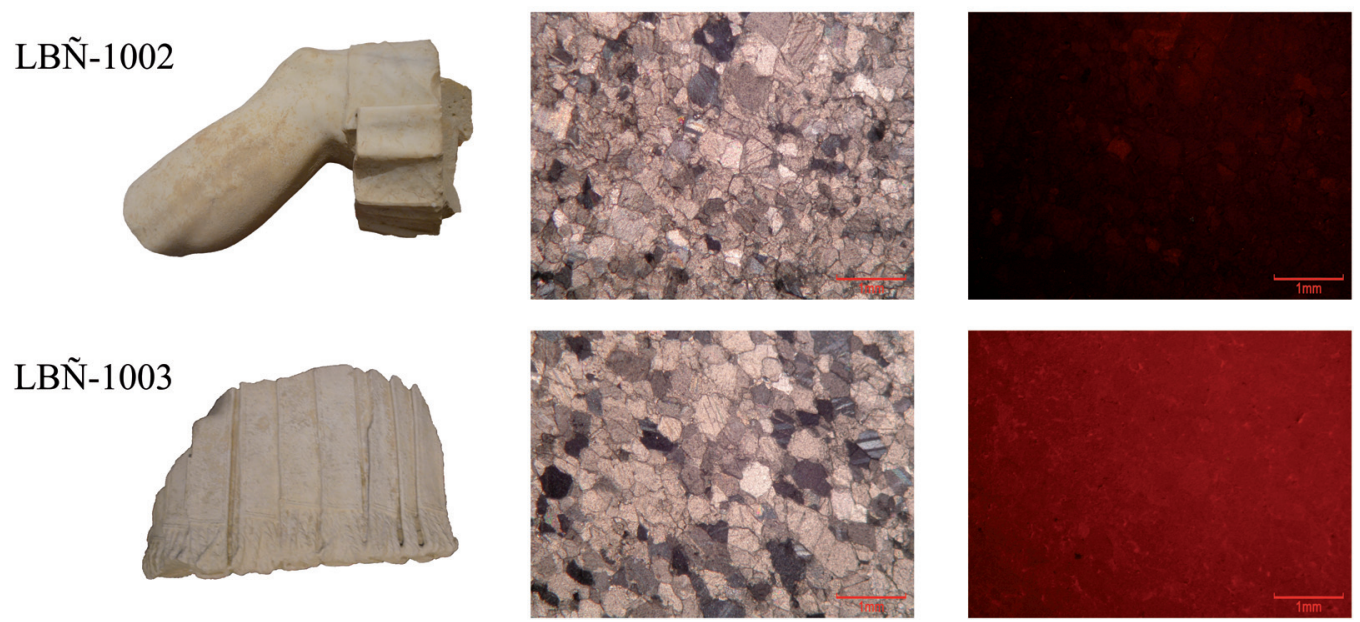

LBÑ-1004
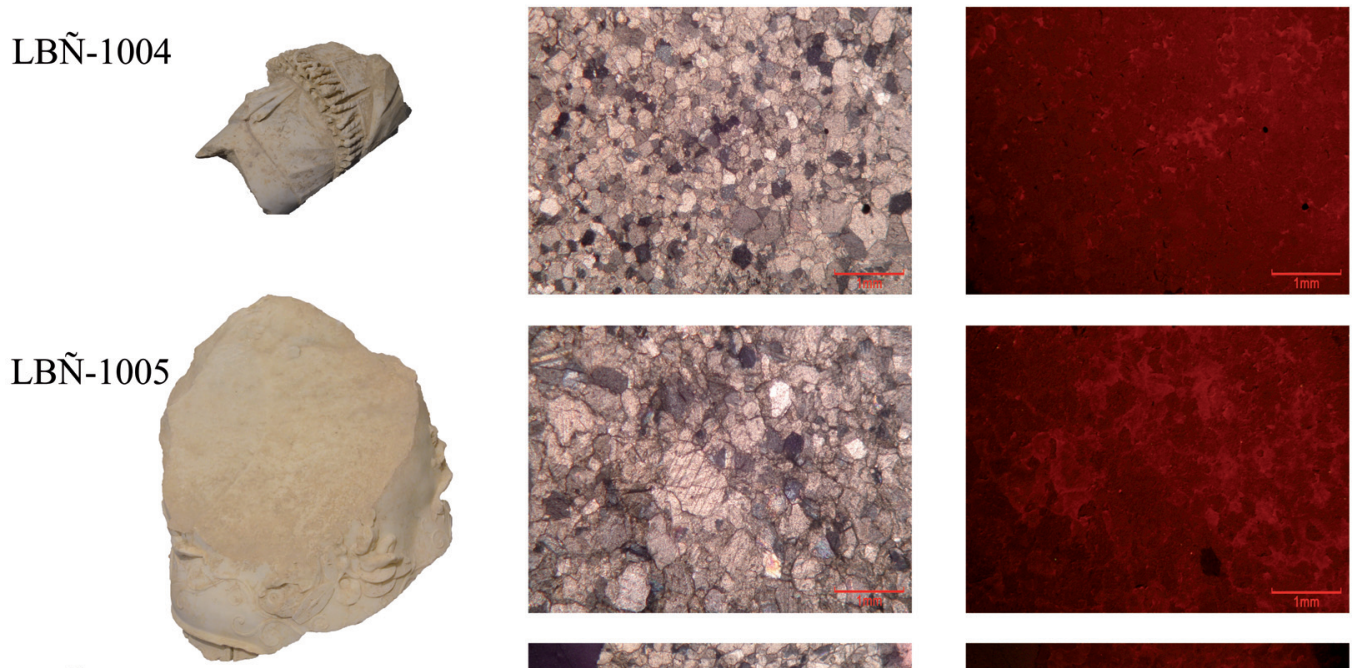

LBÑ-1006
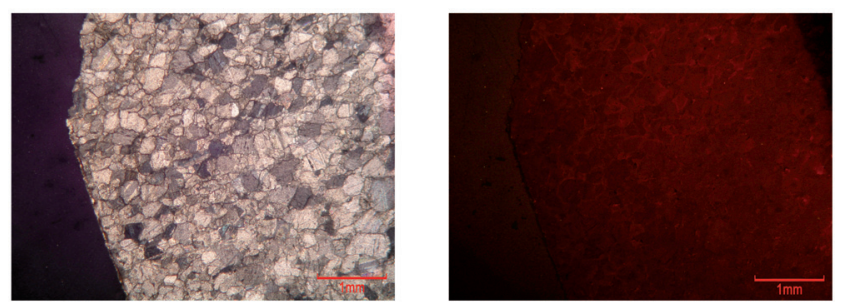

LBÑ-1007
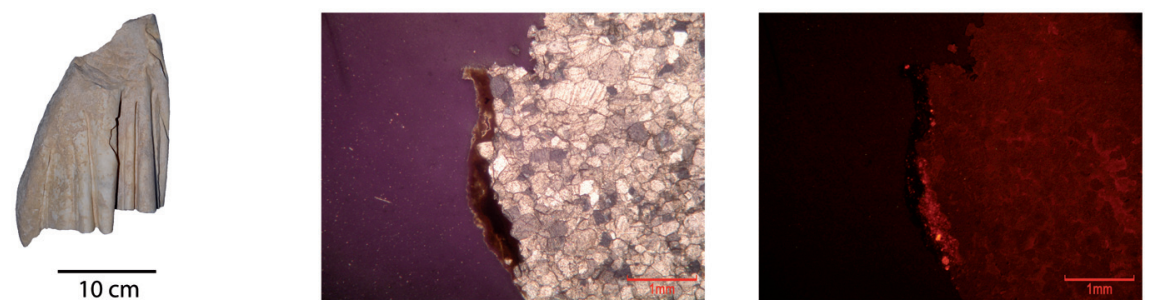

FIG. 1. Aspecto de los fragmentos escultóricos analizados (izquierda) y microfotografías correspondientes en condiciones de nícoles cruzados (centro) y de catodoluminiscencia (derecha) (Fuente: Unitat d'Estudis Arqueomètrics del Institut Català d'Arqueologia Clàssica, Tarragona). 
de isótopos estables del Istituto di Geologia Ambientale e Geoingegneria del Consiglio Nazionale delle Ricerche, Roma. Se han tomando microfotografías de todas las muestras -mediante una cámara Nikon COOLPIX MDC Lens- en condiciones de luz polarizada plana o nícoles paralelos -NP-, luz polarizada cruzada o nícoles cruzados $-\mathrm{NC}-\mathrm{y}$ de su catodoluminiscencia $-\mathrm{CL}-$ para facilitar el estudio y comparación. El análisis de isótopos estables de $\mathrm{C}$ y $\mathrm{O}$ se ha realizado mediante un espectrómetro de masas de relaciones isotópicas-IRMS Finnigan MAT 252. El dispositivo automático de preparación de muestras Finnigan MAT Kiel II se ha utilizado previamente de acuerdo con el procedimiento recomendado (McCrea, 1950), expresando los resultados en tantos por mil (\%o) respecto al estándar internacional PDB -Pee Dee Belemnite-.

Finalmente, valorando los resultados obtenidos, la muestra se ha comparado con otras muestras de referencia de los principales tipos de mármol empleados en época romana, valorando los resultados de varios análisis como un estudio multimétodo (Moens et al., 1992; Lapuente et al., 2000; Gorgoni et al., 2002; Attanasio et al., 2006). Para tal fin, se han empleado los materiales de referencia depositados en el Laboratorio para el Estudio de Materiales Lapídeos de la Antigüedad de la UAB, junto con la colección de muestras depositadas en la Unidad de Estudios Arqueométricos del ICAC.

\section{Resultados analíticos}

El conjunto de muestras analizadas presenta unas características macroscópicas análogas correspondiéndose con un mármol de color blanco uniforme. Presentan un tamaño de grano fino, una textura macroscópica o estructura homogénea y un grado de translucidez elevado.

Mediante el estudio microscópico, ha sido posible corroborar que las características presentadas por todas las muestras son muy similares (Fig. 1). Son mármoles de composición calcítica, su fábrica es isótropa y su textura granoblástica débilmente inequigranular en mosaico.

Sus cristales de calcita presentan un tamaño de grano fino, con un tamaño máximo de grano -MGS- de 0,70 mm. Dichos cristales están bien formados, con una distribución uniforme y presentan contactos cristalinos de morfologías -GBSprincipalmente curvas acompañados en menor medida de contactos de morfologías cóncavo-convexas, rectas que conforman raramente puntos triples y suturadas no interpenetradas. Presentan abundantes maclas y exfoliaciones bastante bien formadas y sin deformaciones intragranulares.

Como minerales accesorios presentan pequeños cristales de mica -con un tamaño máximo de 0,07 mm- aislados y formando pequeños agregados cristalinos en un porcentaje menor al $1 \%$. Las pequeñas partículas que enturbian algunos de los cristales de calcita podrían corresponderse con un pequeño porcentaje de materia orgánica dispersa.

La catodoluminiscencia de todas las muestras (Fig. 1) es muy homogénea, de intensidad baja y de color rojo oscuro -característica del mármol estatuario de Carrara (Barbin et al., 1992) - salvo la muestra LBÑ1002 que, siendo igualmente homogénea, presenta una intensidad menor o muy baja y un color rojo-castaño oscuro. Se presentan dispersos por la muestra cristales aislados con una luminiscencia algo más intensa.

Las relaciones isotópicas obtenidas de $\delta^{13} \mathrm{C}$ y $\delta^{18} \mathrm{O}$ presentan unos valores muy similares, resultando compatibles únicamente con la señal isotópica propia del mármol de Carrara, especialmente los procedentes de los sectores de Miseglia y Torano (Herz y Dean, 1986; Gorgoni et al., 2002), entre los mármoles de grano fino estudiados (Fig. 2). Solamente la muestra LBÑ 1002, con un valor de $\delta^{13} \mathrm{C}$ algo superior, se individualiza del resto en este aspecto.

\section{Conclusiones}

La valoración de todas las características en conjunto, confrontando los resultados con la colección de referencia del LEMLA, permite identificar el tipo de mármol utilizado. Este material se corresponde con el mármol de Carrara o marmor Lunense (Liguria, Italia), siendo esta identificación de material compartida por las 6 muestras analizadas -piernas, faldellín, hombro, coraza, mano y paludamentum-.

Todas ellas presentan características que concuerdan con la variedad más común del mármol de Carrara, como su grano fino, falta de deformación, 
catodoluminiscencia y señal isotópica. Sin embargo, destacan algunos rasgos que difieren completamente de la caracterización petrográfica común del Carrara, como son: textura granoblástica y escasos puntos triples y, sobre todo, un grado de translucidez elevado que normalmente, en sus variedades más comunes, es muy bajo o nulo.

La revisión de la bibliografía disponible, referente a la caracterización e identificación en piezas arqueológicas del mármol de Carrara (Dolci, 1980; Herz y Dean, 1986; Barbin et al., 1992; Lapuente et al., 1999; Attanasio et al., 2000), ha permitido determinar que la muestra pertenece a la variedad estatuaria del mármol de Carrara; siendo esta variedad la que presenta, asimismo, unas características más alejadas de la variedad común y más próximas a las presentes en la muestra estudiada. Quedando por tanto explicado que se identifique un mármol blanco de grano fino y alto grado de translucidez como mármol de Carrara.

Los frentes de cantera de donde se extraía en la Antigüedad esta variedad se sitúan en las áreas o sectores de Miseglia y Torano (Herz y Dean, 1986), que junto con el resto de sectores pertenecen a una extensa formación geológica del Jurásico inferior -Hettangiense (Herz et al., 1999: 101-102)-.

Conviene aclarar que la muestra LBÑ 1002 presenta una ligera divergencia respecto del resto de muestras analizadas, aunque no significativa a la hora de determinar su procedencia. Esta diferenciación se debe a una intensidad de luminiscencia muy baja y oscura y un valor isotópico $\delta^{13} \mathrm{C}$ algo superior al que presentan las otras muestras. No obstante, LBÑ 1002 procede igualmente de estos sectores, pero de un frente de extracción diferente al del resto de las muestras analizadas.

El conjunto de estas muestras es un claro exponente de la mejor variedad de mármol blanco de Carrara estatuario, destinado a esculturas de especial importancia como la magnífica cabeza velada de Augusto hallada en Augusta Emerita (Lapuente et al., 1999) o, ya en una cronología muy posterior, en el impresionante David de Miguel Ángel esculpido en la Florencia de 1504 (Attanasio et al., 2005).

El mármol de Luni-Carrara llega a las costas mediterráneas de Hispania de una manera regular a partir de la época augústea, siendo Tarraco y Carthago Nova las receptoras principales de marmor Lunense (Gutiérrez García-Moreno y Rodà, 2012: 294). Recientemente se localizó en Llivia, en la Cerdanya, una estatua de mármol de Carrara, de tamaño superior al natural, correspondiente a un emperador divinizado o a alguna escultura ideal, que pone de manifiesto la fuerza con que el mensaje del poder y la propaganda política llegaron hasta los rincones más insospechados (Rodà, 2007: 742; Fabre et al., 1991: 189), estas circunstancias podrían ser semejantes a las acontecidas en la ciudad romana de Los Bañales gracias al hallazgo de estos fragmentos de mármol de Carrara pertenecientes a una thoracata imperial, de posible datación domicianea y que, lógicamente, vuelve a evidenciar la apertura de este municipio romano a los influjos del exterior. 


\section{Bibliografía}

Attanasio, D.; Armiento, G.; Brilli, M.; Emanuele, M. C.; Platania, R. y Turi, B. (2000): "Multimethod Marvel provenance determinations: the Carrara marbles as a case study for the combined use of isotopic, electron spin resonante and petrographic data", Archaeometry, 42-2, pp. 257-272.

Attanasio, D.; Brilli, M. y Ogle, N. (2006): The isotopic signature of classical marbles. Roma.

Attanasio, D.; Platania, R. y Rocchi, P. (2005): "The marble of the David of Michelangelo: a multi-method analysis of provenance", Journal of Archaeological Science, 32, pp. 1369-1377. http://dx.doi.org/10.1016/j.jas.2005.03.013

Barbin, V.; RAMSEYer, K.; DeCrouez, D.; Burns, S. J.; Chamay, J. y Maier, J. L. (1992): "Cathodoluminescence of White Marbles - an Overview", Archaeometry, 34, pp. 175-183. http://dx.doi.org/10.1111/j.1475-4754.1992.tb00490.x

DolcI, E. (1980): Carrara Cave Antiche. Viareggio.

FABRe, G.; MAYER, M. y RodÀ, I. (1991): Inscriptions romaines de Catalogne-IRC, III. Paris.

Gorgoni, C.; Lazzarini, L.; Pallante, P. y Turi, B. (2002): "An updated and detailed mineropetrographic and $\mathrm{C}-\mathrm{O}$ stable isotopic reference database for the main Mediterranean marbles used in antiquity". En Herrmann, J. J.; Herz, N. y Newman, R. (eds.): Interdisciplinary Studies on Ancient Stone. London, pp. 115-131.

Gutiérrez García-Moreno, A. y RodÀ, I. (2012): "El mármol de Luni-Carrara en la fachada mediterránea de Hispania”. En KeAY, S. (ed.): Rome, Portus and the Mediterranean. Archaeological Monographs of The British School at Rome, 21. London, pp. 293-312.

Herz, N. y DeAn, N. E. (1986): "Stable isotopes and archaeological geology: the Carrara marble, northern Italy", Applied Geochemistry, 1, pp. 139-151. http://dx.doi.org/10.1016/0883-2927(86)90045-4
Herz, N.; Holbrow, K. A. y Sturman, Sh. G. (1999): "Marble sculpture in the National Gallery of Art: a provenance study". En SchVoerer, M. (ed.): Archéomatériaux - Marbres et Autres Roches (ASMOSIA IV). Bordeaux, pp. 101-110.

Lapuente, P.; Turi, B. y Blanc, Ph. (2000): "Marbles from Roman Hispania: stable isotope and cathodoluminescence characterization", Applied Geochemistry, 15, pp. 1469-1493.

http://dx.doi.org/10.1016/S0883-2927(00)00002-0

LaPuente, P.; Turi, B.; LazZarini, L. y Nogales, T. (1999): "Provenance investigation of White marble sculptures from Augusta Emerita, Hispania". En Schvoener, M. (ed.): Archéomateriaux. Marbles et autres roches (ASMOSIA IV). Bordeaux, pp. 111-116.

Lazzarini, L.; Moschini, G. y Stievano, B. M. (1980): "A contribution to the identification of Italian, Greek and Anatolian marbles through a petrological study and the evaluation of the $\mathrm{Ca} / \mathrm{Sr}$ ratio", Archaeometry, 22, pp. 173-183.

http://dx.doi.org/10.1111/j.1475-4754.1980.tb00940.x

MCCREA, J. M. (1950): "On the isotopic chemistry of carbonates and the palaeotemperature scale", Journal Chemical Physics, 18, pp. 849-857.

http://dx.doi.org/10.1063/1.1747785

Moens, L.; De Paepe, P. y Waelkens, M. (1992): "Multidisciplinary research and cooperation: keys to a successful provenance determination of white marbles". En Waelkens, M.; Herz, N. y Moens, L. (eds.): Ancient stones: Quarrying, trade and provenance. Interdisciplinary studies on stones and stone technology in Europe and near East from Prehistoric to the Early Christian Period (ASMOSIA II). Acta Archaeologica Lovaniensia, Monographie 4. Leuven, pp. 247-254.

RoDÀ, I. (2007): “Documentos e imágenes de culto imperial en la Tarraconense septentrional". En Nogales, T. y GonzÁlez, J. (eds.): Culto imperial. Politica y Poder: Actas del congreso internacional culto imperial: politicas y poder. Roma, pp. 739-761. 